\title{
ARTICLE Insulin modulates the strong reinforcing effects of nicotine and changes in insulin biomarkers in a rodent model of diabetes
}

\author{
Bryan Cruz $\mathbb{D}^{1}$, Rodolfo J. Flores ${ }^{1}$, Kevin P. Uribe ${ }^{1}$, Evangelina J. Espinoza ${ }^{1}$, Charles T. Spencer $\mathbb{D}^{2}$, Katherine M. Serafine ${ }^{1}$, \\ Arbi Nazarian ${ }^{3}$ and Laura E. O'Dell ${ }^{1}$
}

This study examined whether the strong reinforcing effects of nicotine and changes in insulin biomarkers observed in diabetic rats are modulated via insulin. A model of diabetes was employed involving administration of streptozotocin (STZ), which produces hypoinsulinemia in rats. The present study included vehicle- or STZ-treated rats that received sham surgery or insulin pellets. Two weeks later, the rats were given extended access to intravenous self-administration (IVSA) of saline or nicotine. Concomitant changes in food intake, water responses, and body weight were assessed during 12 days of IVSA. After the last session, plasma levels of insulin, leptin, amylin, and glucagon-like peptide-1 (GLP-1) were assessed using Luminex technology. In a separate cohort, phosphorylated insulin receptor substrate-2 (pIRS-2) and insulin growth factor-1 receptor $\beta$ (IGF-1R $\beta$ ) were assessed in the nucleus accumbens (NAC) and ventral tegmental area (VTA) of vehicle- or STZ-treated rats that received sham surgery or an insulin pellet. STZ-treated rats displayed an increase in glucose levels, a decrease in body weight, and an increase in nicotine, food, and water intake relative to controls. STZ-treated rats also displayed a decrease in plasma insulin and leptin levels and an increase in amylin and GLP-1 levels relative to controls. Importantly, all of the STZ-induced changes in behavior and insulin biomarkers were prevented by insulin supplementation. STZ-treated rats also displayed a decrease in pIRS- 2 and IGF-1R $\beta$ in the NAc (but not VTA), an effect that was also prevented by insulin. These data suggest that insulin systems in the NAc modulate the strong reinforcing effects of nicotine in male diabetic rats.

Neuropsychopharmacology (2019) 44:1141-1151; https://doi.org/10.1038/s41386-018-0306-3

\section{INTRODUCTION}

There is growing evidence that patients with diabetes display a higher propensity for tobacco use than the general population. For example, patients with Type 1 diabetes report higher rates of current smoking (12.3\%) than non-diabetic smokers (8.6\%) [1]. Also, patients with diabetes report lower quit rates and display a greater concern for weight gain if they quit smoking as compared to non-diabetic smokers [2]. Patients with diabetes also experience more intense negative affective states and depression symptoms during smoking abstinence [3, 4]. Unfortunately, patients with diabetes that smoke also experience greater mortality rates and health complications, such as disrupted glucose homeostasis $[5,6]$. Despite the magnitude of the problem associated with diabetes and smoking, the underlying mechanisms that promote tobacco use among patients with diabetes remain unknown. Given that the etiological origin of diabetes involves a lack of insulin signaling, the possibility exists that a disruption in insulin systems results in greater rewarding effects of nicotine, the main psychoactive compound that motivates tobacco use.

Diabetes causes metabolic complications and an elevation in blood glucose levels via a decrease in insulin production from $\beta$ cells in the pancreas (Type 1 diabetes) or development of insulin resistance (Type 2 diabetes). Prior work in our laboratory has examined the behavioral effects of nicotine in a rodent model of diabetes involving administration of streptozotocin (STZ) [7, 8]. STZ is taken up by glucose transporters, and this drug displays the highest affinity for type 2 transporters that are prevalent in the pancreas. When STZ is administered to rodents, DNA methylation induces cellular toxicity to the insulin-producing $\beta$-cells of the pancreas [9]. The disruption of insulin release from the pancreas mimics the etiology of Type 1 diabetes and later stages of Type 2 diabetes.

Previous work in our laboratory has revealed that STZtreated rats display greater nicotine intake compared to healthy controls in a rodent model involving $23-\mathrm{h}$ access to intravenous self-administration (IVSA) [8]. Consistent with the latter finding, a subsequent report revealed that STZ-treated rats display a more robust conditioned place preference (CPP) produced by nicotine as compared to healthy control rats [7]. These studies suggest that a lack of insulin leads to an increase in the rewarding effects of nicotine. Previous work has also shown that insulin-associated metabolic proteins, including amylin, GLP-1, leptin, and insulin cross the blood-brain barrier and modulate motivated behavior [10-13]. To examine the role of insulin in modulating the behavioral and biochemical effects of nicotine, the present study assessed changes in an array of insulin-related biomarkers following chronic nicotine IVSA in diabetic rats that received insulin supplementation.

\footnotetext{
${ }^{1}$ Department of Psychology, The University of Texas at El Paso, 500 West University Avenue, El Paso, TX, USA; ${ }^{2}$ Department of Biological Sciences, The University of Texas at EI Paso, 500 West University Avenue, El Paso, TX, USA and ${ }^{3}$ Department of Pharmaceutical Sciences, Western University of Health Sciences, Pomona, CA, USA Correspondence: Laura E. O'Dell (lodell@utep.edu)
}

Received: 13 July 2018 Revised: 17 November 2018 Accepted: 15 December 2018

Published online: 7 January 2019 
The rewarding effects of nicotine are modulated via dopamine transmission in the mesolimbic pathway, which originates in the VTA and terminates in several forebrain structures including the NAC [14-16]. Previous studies have revealed that there is a large distribution of insulin receptors in the NAC and the VTA that modulate motivated behavior [12, 17, 18]. There are insulin receptors on cholinergic interneurons in the NAc, providing a mechanism by which changes in insulin signaling may influence the behavioral effects of nicotine [19]. Within the NAc, STZ-treated rats display a down-regulation of pIRS-2 and an up-regulation of protein kinase B, an insulin-related marker coupled to pIRS-2 receptors [20]. It is presently unclear whether STZ-treated rats display a change in insulin-signaling proteins in the NAc and/or VTA that promotes the rewarding effects of nicotine in diabetic rats.

The present study examined the role of insulin in modulating the strong rewarding effects of nicotine previously observed in STZ-treated rats. It was hypothesized that insulin supplementation would reduce the strong reinforcing effects of nicotine to control levels in STZ-treated rats. This hypothesis was based on the recent finding that STZ-treated rats display an increase in CPP produced by nicotine that was reduced to control levels following insulin supplementation [21]. Also, an intracranial self-stimulation study revealed that STZ-treated rats display a decrease in brain reward function that was reduced to control levels following insulin supplementation [22]. It was also expected that STZ-treated rats would display a decrease in insulin signaling in the NAc given a previous study showing that STZ-treated rats display a reduction in pIRS-2 in the NAc [20].

\section{METHODS AND MATERIALS}

\section{Subjects}

Adult male rats were derived from an out-bred stock of Wistar rats that were maintained on a 12-h light/dark cycle (lights OFF at 6:00 $\mathrm{PM}$ and $\mathrm{ON}$ at 6:00 AM) in a humidity- and temperature-controlled vivarium $\left(22^{\circ} \mathrm{C}\right)$. Between postnatal days $52-60$, the rats were handled and weighed for 3-5 days prior to the start of the experiments. The rats had ad libitum access to food and water prior to IVSA testing, and they were allowed to operant respond for food and water without limitations during the IVSA sessions. All procedures were approved by the UTEP Institutional Animal Care and Use Committee.

Overall experimental design

Below is a summary diagram of the overall experimental timeline.
This report consists of two studies that were conducted in separate cohorts of rats. Study 1 employed extended IVSA procedures to examine whether STZ-treated rats display an increase in nicotine intake that is reduced to control levels following insulin supplementation. Specifically, Study 1 compared nicotine IVSA in vehicle-treated $(n=17)$, STZ-treated $(n=16)$, and STZ-treated + insulin $(n=13)$ rats. To examine the role of insulin in nicotine IVSA in the absence of STZ, a separate group of vehicle-treated rats received insulin supplementation $(n=8)$. This study also included vehicletreated rats that received saline IVSA $(n=10)$. Changes in food intake, water responses, and body weight were assessed each day of IVSA. Twenty-four hours after the last IVSA session, metabolic biomarkers were assessed in plasma collected from a subset of rats from Study 1 . Study 2 employed protein analysis procedures to assess changes in insulin biomarkers in the NAc and VTA of STZtreated rats that received insulin supplementation. Specifically, Study 2 compared insulin-signaling proteins in nicotine naive vehicle-treated $(n=6)$, STZ-treated $(n=6)$, or STZ-treated + insulin $(n=5-6)$ rats. Brain tissue was collected 2 weeks after STZ administration to examine protein markers at a time point that corresponded to the onset of IVSA in Study 1.

Diabetes induction and insulin supplementation

Rats received vehicle or STZ administration ( $45 \mathrm{mg} / \mathrm{kg}$, s.c.). STZ was dissolved in citrate buffer ( $0.1 \mathrm{M}$ citric acid and $0.1 \mathrm{M}$ sodium citrate; Sigma-Aldrich, St. Louis, MO, USA). The dose of STZ was selected based on previous work demonstrating that this concentration produces a rapid and reliable increase in glucose levels 3-5 days after STZ administration [7, 8]. Immediately after vehicle or STZ administration, the rats were anesthetized with an isoflurane/oxygen vapor mixture (1-3\%) and received a sham surgery or implanted subcutaneously with 2 insulin pellets based on the manufacturer specifications for the weight of the rats (Linplant Toronto, ON, Canada). According to the manufacturer, each pellet releases $2 \mathrm{U} / 24 \mathrm{~h}$, consistent with physiological levels in humans. Also, the pellets are purported to release insulin for at least 60 days, which exceeds our experimental timeline. Indeed, Table 1 illustrates that the insulin pellets maintained control levels of glucose in STZ-treated rats throughout IVSA testing. Plasma glucose levels were assessed every 2-3 days using a glucose meter calibrated for rodent plasma (AlphaTRAK ${ }^{\circ}$ Abbott Park, IL, USA). A lancet was used to prick the tip of the tail to extract a small drop of blood that was placed on a glucose test strip. For both studies, the rats were tested 2 weeks after vehicle or STZ administration and insulin supplementation.

Study 1: Behavioral analysis
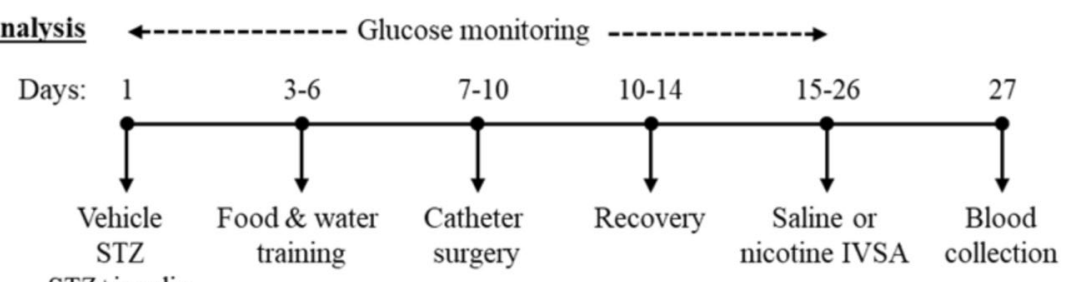

STZ+insulin

Vehicle+insulin

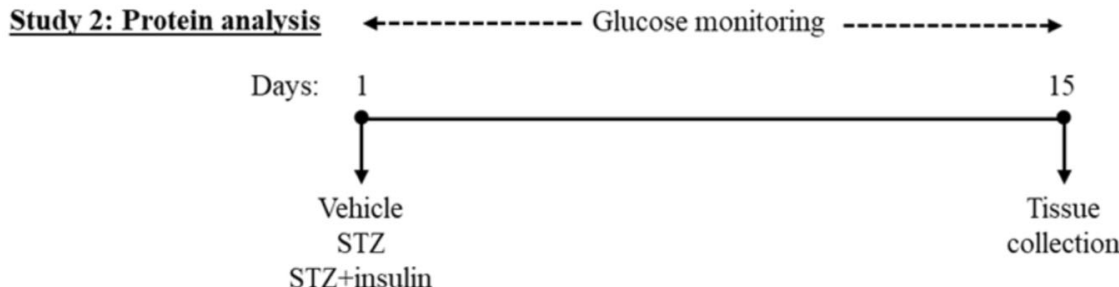


Table 1. Glucose levels $(\mathrm{mg} / \mathrm{dL} \pm \mathrm{SEM})$ across experimental groups that received vehicle or $\mathrm{STZ}$

Study 1: Behavioral analysis

Groups IVSA of $n \quad$ Glucose levels prior

\begin{tabular}{llll} 
& & \multicolumn{1}{l}{ to IVSA } \\
\hline Vehicle-treated & Saline & 10 & $116.2 \pm 6.5$
\end{tabular}

\begin{tabular}{|c|c|c|c|c|c|}
\hline Vehicle-treated & Saline & 10 & $116.2 \pm 6.5$ & $136.0 \pm 3.7$ & Vehicle- \\
\hline Vehicle-treated & Nicotine & 17 & $123.7 \pm 2.8$ & $148.9 \pm 10.4$ & \\
\hline STZ-treated & Nicotine & 13 & $515.5 \pm 17.1^{\dagger}$ & $505.3 \pm 28.4^{\dagger}$ & STZ-trea \\
\hline STZ-treated + insulin & Nicotine & 16 & $116.6 \pm 21.8$ & $127.5 \pm 25.3$ & STZ-trea \\
\hline Vehicle-treated + insulin & Nicotine & 8 & $77.7 \pm 5.9^{*}$ & $86.7 \pm 14.5$ & insulin \\
\hline
\end{tabular}
of IVSA

Ind all oroups $(p \leq 0.05)$

Study 2: Protein analysis

Glucose levels at the end Groups NAc $(n)$ VTA $(n)$ Glucose levels

$\begin{array}{lllll}136.0 \pm 3.7 & \text { Vehicle-treated } & 6 & 6 & 137.6 \pm 5.0 \\ 148.9 \pm 10.4 & & & & \\ 505.3 \pm 28.4^{\dagger} & \text { STZ-treated } & 6 & 6 & 570.0 \pm 23.8^{\dagger} \\ 127.5 \pm 25.3 & \text { STZ-treated }+ & 5 & 6 & 178.5 \pm 22.6 \\ 86.7 \pm 14.5 & \text { insulin } & & & \end{array}$

Indicates different from vehicle-treated rats $(p \leq 0.05)$

Study 1 methods

Study 1 examined the effects of insulin on the reinforcing effects of nicotine and changes in plasma metabolic biomarkers in vehicle- and STZ-treated rats. The rats were tested in operant chambers that were housed inside sound-attenuated ventilated cubicles (Med Associates, St. Albans, VT, USA). During IVSA testing, the rats lived in a dedicated operant chamber for $23 \mathrm{~h}$ per day. The rats were removed daily from the chambers for $1 \mathrm{~h}$ (11:00 $A M-12: 00 \mathrm{PM})$ to clean the chambers, retrieve the data, and replenish the food and water levels. During that 1-h period, the rats were placed into a home cage in the same testing room, and they were given ad libitum access to food and water.

Prior to IVSA testing, the rats were trained to perform operant responses for food and water for 4-5 days on a fixed ratio (FR) 1 schedule of reinforcement. The total number of food and water operant responses were recorded daily for each rat. The rats were allowed to nose-poke in a food receptacle that delivered palatable chow from a pellet dispenser $(45 \mathrm{mg} / \mathrm{kg}$; Bio-Serv, Frenchtown, NJ, USA). The rats also performed nose-poke responses in a separate hole located in the opposite side of the food pellet dispenser and levers. Each nose poke dispensed $0.1 \mathrm{~mL}$ of water into an adjacent dipper cup via a syringe pump. All rats reached stable levels of responding for food and water in the initial 1-2 days of food and water training.

The rats were then returned to their home cage and allowed to free feed the day before the catheterization surgery. The rats were anesthetized using an isoflurane/oxygen vapor mixture (1-3\%) and were then prepared with IV catheters into the jugular vein, as previously described [8, 23, 24]. After surgery, the rats were allowed to recover for 4 days in their home cage where they were given ad libitum access to food and water. The catheters were flushed daily $(0.3-0.5 \mathrm{~mL})$ with an antibiotic solution containing Cefazolin ${ }^{\oplus}$ dissolved in saline and heparin (30 USP units $/ \mathrm{mL}$ ).

Two weeks after STZ administration, the rats were given extended access to saline or nicotine by introducing two novel levers (active and inactive) on the first IVSA session. Presses on the active lever delivered $0.1 \mathrm{~mL}$ of saline or nicotine via a syringe pump. Each response on the active lever illuminated a $28 \mathrm{~V}$ cue light above the lever at the onset of the $1 \mathrm{~s}$ infusion, and the cue light was terminated after a $20 \mathrm{~s}$ time-out period. Presses on the active lever during the time-out period had no scheduled consequences. (-)Nicotine hydrogen tartrate salt (Sigma-Aldrich, St. Louis, MO, USA) was dissolved in $0.9 \%$ sterile saline and adjusted to $7.4 \mathrm{pH}$. The nicotine solutions were prepared every day and adjusted to the rats' body weight from the previous day. The doses of nicotine were selected based on previous work in our laboratory using 23-h access to nicotine IVSA $[8,25]$. Responses on the active lever delivered nicotine on a FR-1 schedule of reinforcement. An escalating dose regimen was employed, whereby rats received 0.03 then 0.06 and then $0.09 \mathrm{mg} / \mathrm{kg} / 0.1 \mathrm{~mL}$ infusion. Each dose was available for 4 consecutive days with 3 intervening days of forced abstinence prior to initiating the next higher dose of nicotine. Three rats were removed from our final analysis because of catheter leakage, 1 rat was removed due to a faulty active lever, and 8 STZ-treated rats were eliminated that displayed glucose levels greater than $700 \mathrm{mg} / \mathrm{dL}$ and/or were too sick to continue behavioral testing.

Twenty-four hours after the last IVSA session, the rats were sacrificed and trunk blood was collected to assess changes in plasma metabolic biomarkers. The blood was centrifuged for 15 min at $6900 \mathrm{rpm}$ at $4{ }^{\circ} \mathrm{C}$. The plasma was extracted and stored at $-80^{\circ} \mathrm{C}$ until assayed using commercially available MilliPlex ${ }^{\oplus}$ kits (Millipore Sigma, MA, USA) specific for insulin, leptin, amylin, and GLP-1. The plates were analyzed on a MAGPIX ${ }^{\oplus}$ system using xPONENT ${ }^{\oplus}$ software. The MAGPIX ${ }^{\oplus}$ system was calibrated before each assay using calibration and performance verification kits (Luminex Corporation Inc., Austin, TX, USA).

\section{Study 2 methods}

Study 2 assessed changes in insulin-signaling proteins in the NAc and VTA of vehicle- and STZ-treated rats that received insulin supplementation. This study was conducted in nicotine-naïve rats in order to assess the effects of insulin in the absence of any confounding effects produced by chronic nicotine exposure. Two weeks after vehicle or STZ administration, the rats were sacrificed and the NAC and VTA were dissected from vehicle-, STZ-, and STZtreated + insulin rats. The tissue was flash frozen and stored at $-80^{\circ} \mathrm{C}$ until assayed. The tissue was homogenized in lysis buffer containing $10 \mathrm{mM}$ HEPES, $10 \mathrm{mM} \mathrm{KCl}, 1.5 \mathrm{mM} \mathrm{MgCl}, 1 \%$ Igepal (Sigma-Aldrich, St. Louis, MO, USA) dissolved in a protease and phosphatase inhibitor cocktail (Roche, Indianapolis, IN, USA), as previously described [26]. The tissue homogenates were then centrifuged at $4{ }^{\circ} \mathrm{C}$ for $5 \mathrm{~min}$ at $14,000 \mathrm{rpm}$, and the resultant supernatant was collected. Protein concentrations $(25 \mu \mathrm{g})$ were quantified from the cytosol using a Bio-Rad Protein Assay Standard II Kit with bovine serum albumin as the standard solution (Bio-Rad Laboratories, Hercules, CA, USA). Insulinsignaling proteins were separated via SDS-PAGE then transferred to nitrocellulose membranes (pIRS-2) or PVDF (IGF-1Rß). Nitrocellulose membranes and PVDF were blocked in 5\% non-fat dry milk dissolved 1X-Tris-buffered saline containing Tween 20 (1X-TBST; Cell-Signaling Technology Inc., Danvers, MA, USA). Primary antibodies specific for pIRS-2 (186 kDa; 1:2000) and IGF-1Rß (95 $\mathrm{kDa} ; 1: 2000)$ were incubated in $5 \%$ non-fat dry milk dissolved in $1 \times$-TBST and probed overnight at $4{ }^{\circ} \mathrm{C}$. Subsequently, membranes were repeatedly washed in $1 \times$-TBST and re-probed for corresponding HRP-conjugated secondary antibodies specific for antimouse IgG $(1: 10,000)$ and anti-rabbit IgG $(1: 10,000)$. Membranes were imaged on a ChemiDoc ${ }^{\mathrm{TM}}$ XRS + in chemiluminescent reagents for protein intensity. All blots were normalized to 
a-tubulin (52 kDa; 1:6000) and analyzed using ImageJ software provided by $\mathrm{NIH}$.

\section{Statistics}

Separate 3-way mixed-measures analyses of variance (ANOVA) were used to analyze intake, infusions, active lever presses, and inactive lever presses (Fig. 1) as well as food intake, water responses, and changes in body weight (Fig. 2). For the behavioral analyses, treatment was the between-subject factor and dose (saline or escalating doses of nicotine) and day were withinsubject factors. For the behavioral results, a test for the assumption of multiple sphericity was applied using the Huynh-Feldt correction factor. As a result, appropriate corrections were applied to the degrees of freedom resulting in more conservative $F$-ratios for the behavioral measures. For the glucose analysis of Study 1, a 2-way mixed-measures ANOVA was used with treatment as a between-subject factor and time as a withinsubject factor (prior to IVSA versus after the last day of IVSA). For the glucose analysis of Study 2, a 1-way ANOVA was used with treatment as a between-subject factor (Table 1). For each metabolic biomarker, separate 1-way ANOVAs were used with treatment as a between-subject factor (Fig. 3). For the insulinsignaling proteins, separate 2-way ANOVAs were used with treatment and brain region (NAC or VTA) as between-subject factors. Post-hoc analyses compared group differences following significant interaction effects collapsed across day or dose depending on which main effects were observed using Fisher's LSD test $(p \leq 0.05)$.

\section{RESULTS}

Table 1 illustrates mean $( \pm$ SEM) plasma glucose levels. For Study 1, the initial analysis of glucose levels revealed that there was no interaction between treatment and time $\left[F_{(4,59)}=0.54, p=0.71\right]$. However, this analysis revealed a main effect of treatment $\left[F_{(4,59)}\right.$ $=183.2, \quad p \leq 0.0001]$, with STZ-treated rats displaying higher glucose levels as compared to all other groups both prior to and at the end of IVSA $\left({ }^{\dagger} p \leq 0.01\right)$. Vehicle-treated rats that received insulin displayed lower glucose levels than their respective vehicle-treated rats that pressed for nicotine $\left({ }^{*} p \leq\right.$ 0.01 ), suggesting that the insulin regimen produced a degree of hypoglycemia in healthy animals. For Study 2 , the analysis revealed a main effect of treatment $\left[F_{(2,14)}=137.2, p \leq 0.0001\right]$, with STZ-treated rats displaying higher glucose levels than all other groups $\left({ }^{\dagger} p \leq 0.01\right)$. Importantly, in both Study 1 and 2, STZtreated rats that received insulin displayed similar glucose levels relative to their respective vehicle-treated controls.

Figure 1 illustrates mean $( \pm$ SEM) intake, infusions, active lever presses, and inactive lever presses. The initial analysis of daily intake (panel A) revealed that there was no interaction between treatment, dose, and day $\left[F_{(17.1,252.4)}=1.12, p=0.32\right]$. However, this analysis revealed a significant interaction between treatment and dose $\left[F_{(7.6,113.5)}=4.23, p \leq 0.0001\right]$. Thus, the panel on the right reflects intake collapsed across day. Post-hoc analyses revealed that all groups that pressed for nicotine displayed higher intake as compared to vehicle-treated rats that pressed for saline $\left({ }^{*} p \leq 0.01\right)$. Importantly, STZ-treated rats displayed higher levels of intake at each dose of nicotine as compared to all other groups $\left({ }^{\dagger} p \leq 0.05\right)$. There were no significant differences in nicotine intake between vehicle- and STZ-treated + insulin groups.

The analysis of infusions (panel $B$ ) revealed that there was no interaction between treatment, dose, and day $\left[F_{(20.0,296.1)}=1.15, p\right.$ $=0.30]$. However, there was a main effect of treatment $\left[F_{(4,59)}=\right.$ $17.34, p \leq 0.0001]$. Thus, the panel on the right reflects infusions collapsed across dose and day. Post-hoc analyses revealed that all groups that pressed for nicotine displayed more infusions as compared to vehicle-treated rats that pressed for saline $\left({ }^{*} p \leq 0.01\right)$. Importantly, STZ-treated rats displayed more nicotine infusions as compared to all other groups $\left({ }^{\dagger} p \leq 0.05\right)$. There were no differences in the number of nicotine infusions between vehicleand STZ-treated + insulin groups.

The analysis of active lever presses (panel C) revealed that there was no interaction between treatment, dose, and day $\left[F_{(18.1,267.6)}=0.48, p=0.97\right]$. However, there was a main effect of treatment $\left[F_{(4,59)}=20.45, p \leq 0.01\right]$. Post-hoc analyses revealed that both vehicle-treated groups that pressed for nicotine displayed more active lever presses as compared to the vehicletreated group that pressed for saline $\left({ }^{*} p \leq 0.01\right)$. Importantly, STZtreated rats displayed more active lever presses for nicotine as compared to all other groups $\left({ }^{\dagger} p \leq 0.05\right)$. There were no differences in active lever presses between vehicle- and STZtreated + insulin groups. The analysis of inactive lever presses (panel D) revealed that there was no interaction between treatment, dose, and day $\left[F_{(18.1,268.0)}=0.57, p=0.92\right]$. There were also no main effects of treatment $\left[F_{(4,59)}=1.63, p=0.18\right]$ or dose $\left[F_{(1.6,98.8)}=0.75, p=0.69\right]$.

Figure 2 illustrates mean ( \pm SEM) food intake, water responses, and weight change. The analysis of food intake (panel A) revealed that there was no interaction between treatment, dose, and day $\left[F_{(21.1,312.6)}=0.61, p=0.91\right]$. However, there was a main effect of treatment $\left[F_{(4,59)}=14.56, p \leq 0.01\right]$. Post-hoc analyses revealed that vehicle- and STZ-treated + insulin groups that pressed for nicotine displayed less food intake as compared to vehicle-treated controls that pressed for saline $\left({ }^{*} p \leq 0.01\right)$, an effect that illustrates the food suppressant effects of nicotine. Importantly, STZ-treated rats displayed higher levels of food intake as compared to all other groups $\left({ }^{+} p \leq 0.05\right)$. There were no differences in food intake between vehicle- and STZ-treated + insulin groups. The analysis of water responses (panel $B$ ) revealed that there was no interaction between treatment, dose, and day $\left[F_{(11.5,170.7)}=1.04, p=0.41\right]$. However, there was a main effect of treatment $\left[F_{(4,59)}=6.31, p \leq\right.$ $0.0001]$. Post-hoc analyses revealed that STZ-treated rats displayed more water responses than all other groups $\left({ }^{\dagger} p \leq 0.05\right)$. There were no differences in water intake between vehicle- and STZ-treated + insulin groups.

Weight change was calculated by subtracting daily body weight from values collected on the first day of IVSA, such that positive values reflect an increase and negative values reflect a decrease in body weight from the first day of IVSA. The analysis of weight change (panel $C$ ) revealed that there was no interaction between treatment, dose, and day $\left[F_{(21.0,311.0)}=1.15, p=0.29\right]$. However, there was a main effect of treatment $\left[F_{(4,59)}=16.84, p \leq 0.0001\right]$. Post-hoc analyses revealed that vehicle-treated rats that pressed for saline displayed greater increases in body weight as compared to vehicle-, STZ-, and STZ-treated + insulin rats that pressed for nicotine $\left({ }^{*} p \leq 0.01\right)$, an effect that illustrates the weight suppressant effects of nicotine. Importantly, STZ-treated rats displayed lower body weights relative to all other groups $\left({ }^{\dagger} p \leq 0.05\right)$. There were no differences between vehicle- and STZ-treated + insulin groups.

Figure 3 illustrates mean plasma levels ( \pm SEM) of insulin, leptin, amylin, and GLP-1. The analysis of insulin (panel A) revealed a main effect of treatment $\left[F_{(4,43)}=8.62, p \leq 0.0001\right]$. Post-hoc analysis revealed that STZ-treated rats displayed lower levels of insulin as compared to all other groups $\left({ }^{\dagger} p \leq 0.0001\right)$. There was no difference between the vehicle- and STZ-treated + insulin groups. The analysis of leptin (panel B) revealed a main effect of treatment $\left[F_{(4,43)}=11.62, p \leq 0.0001\right]$. STZ-treated rats displayed lower levels of leptin as compared to all other groups $\left({ }^{\dagger} p \leq 0.0001\right)$. There were no differences in leptin levels between vehicle- and STZ-treated + insulin groups. The analysis of amylin (panel $C$ ) revealed a main effect of treatment $\left[F_{(4,43)}=5.43, p \leq 0.001\right]$. STZ-treated rats displayed higher levels of amylin than their respective vehicletreated controls that pressed for nicotine $\left({ }^{\#} p \leq 0.0001\right)$, an effect that illustrates STZ-induced enhancement of amylin levels. Also, vehicle-treated rats that received insulin displayed higher 
Saline IVSA

Vehicle-treated

\section{Nicotine IVSA}

Vehicle-treated

STZ-treated

STZ-treated+insulin

$\square$ Vehicle-treated+insulin
(A)

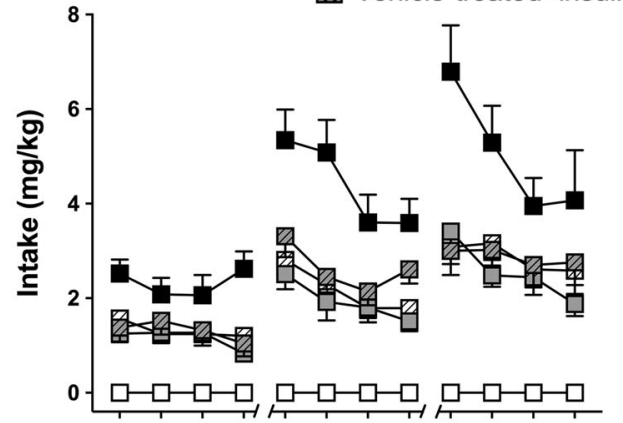

(B)

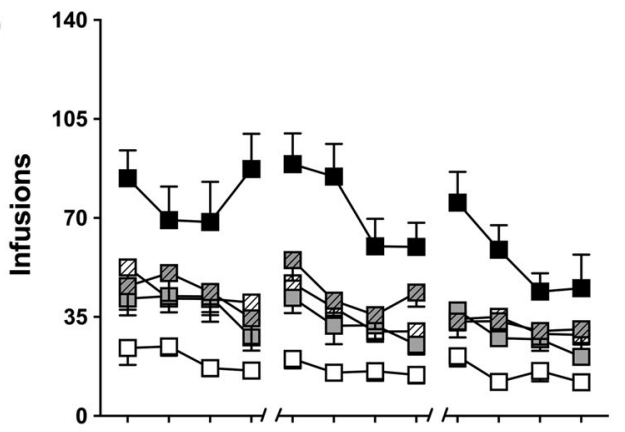

(C)

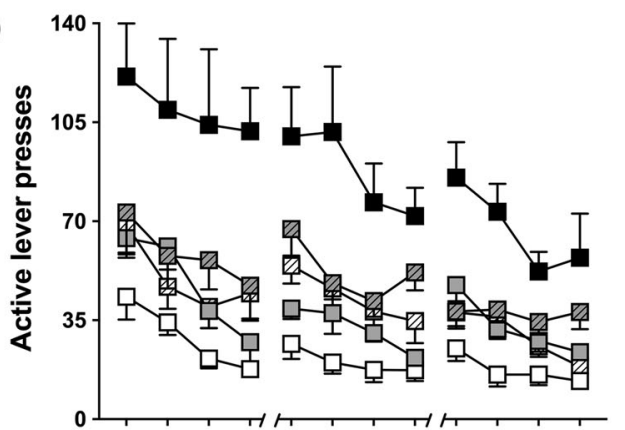

(D)

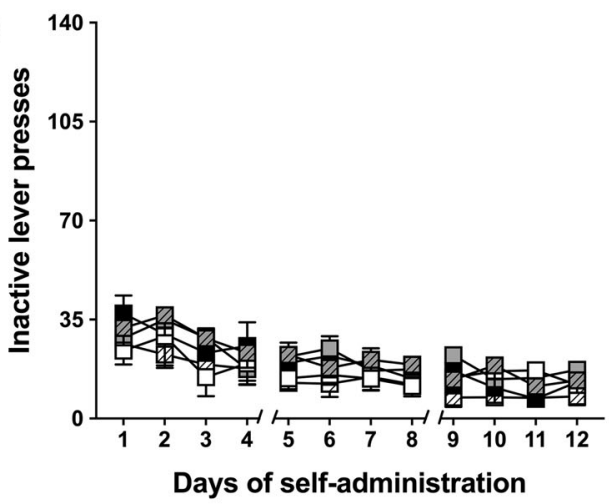

Intake

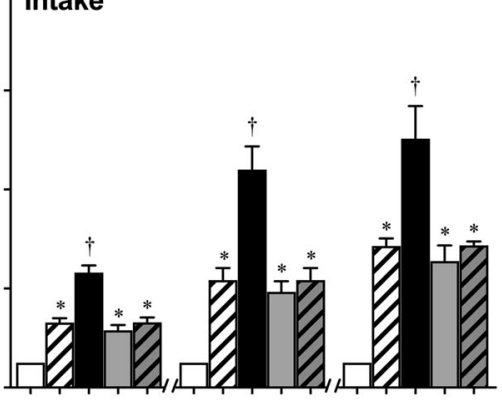

Infusions
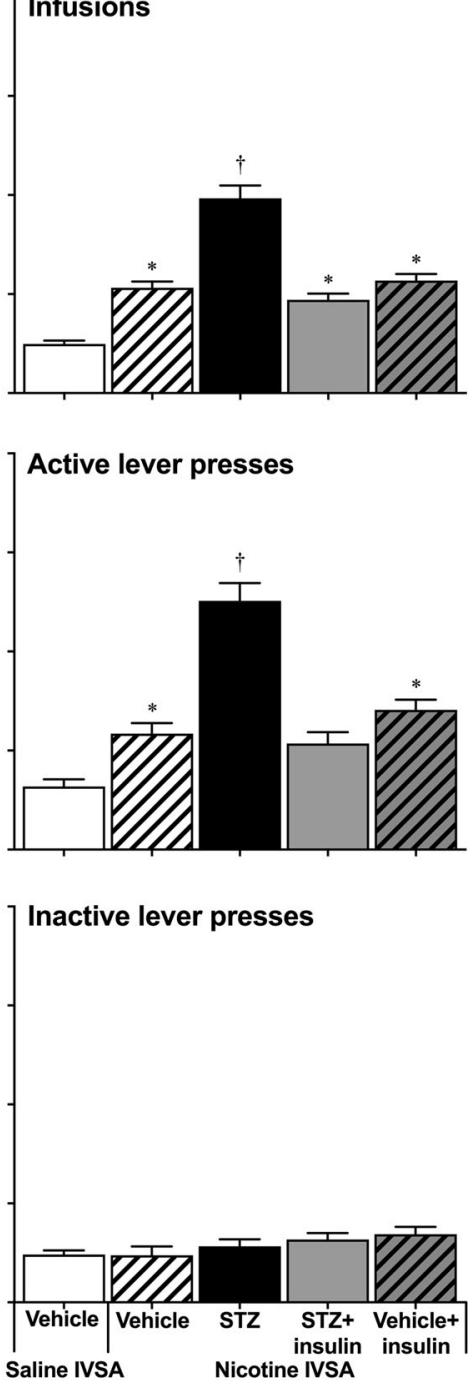

Treatment conditions

Fig. 1 Mean $( \pm S E M)$ nicotine intake (A), nicotine infusions (B), active lever presses (C), and inactive lever presses (D) during each day (left panels) and averaged across days (right panels). The group sizes were as follows: vehicle-treated/saline IVSA ( $n=10)$, vehicle-treated/nicotine IVSA $(n=17)$, STZ-treated/nicotine IVSA $(n=16)$, STZ-treated + insulin/nicotine IVSA $(n=13)$, and vehicle-treated + insulin/nicotine IVSA $(n=8)$. The asterisks $(*)$ denote a significant difference from vehicle-treated/saline IVSA rats, and the daggers $(\dagger)$ denote a difference from all other groups $(p \leq 0.05)$ 


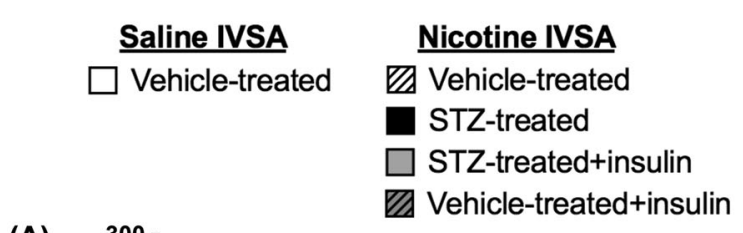

(A)

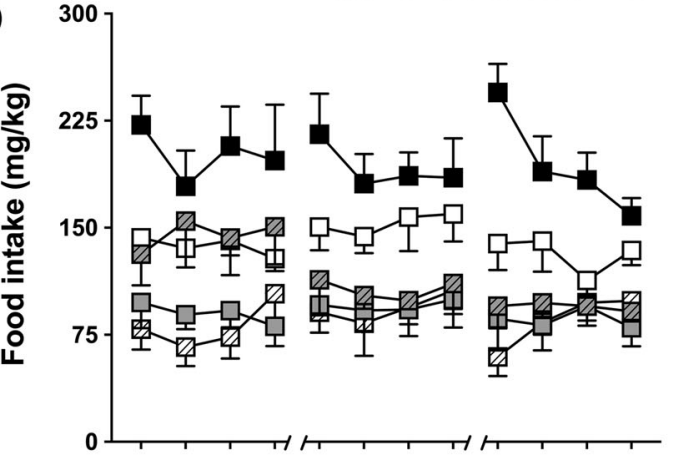

(B)

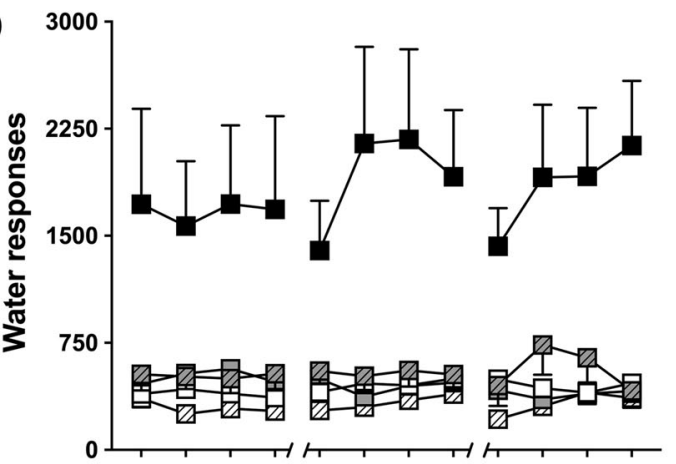

(C)

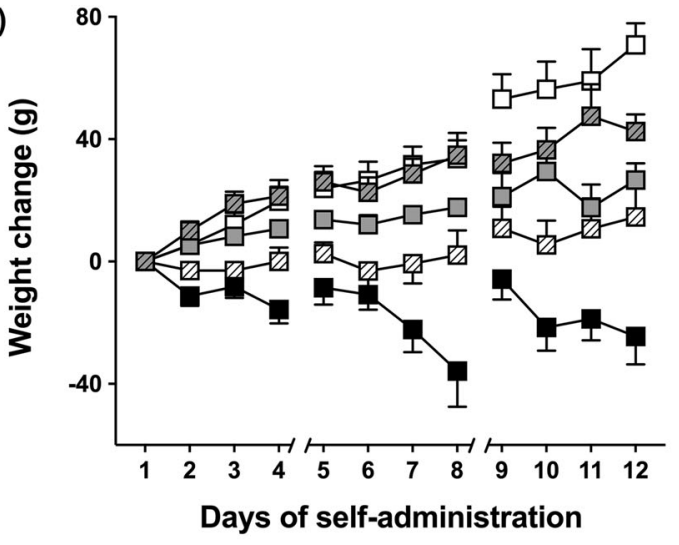

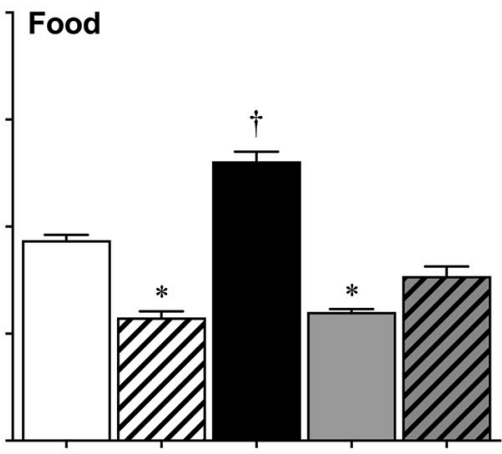
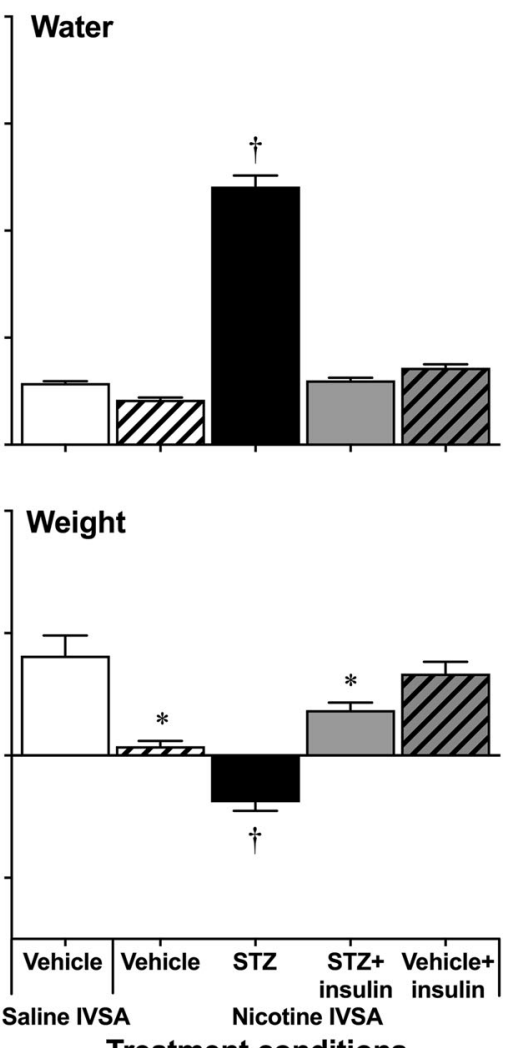

Treatment conditions

Fig. 2 Mean ( \pm SEM) food intake (A), water responses (B), and weight change (C) during each day (left panels) and averaged across days (right panels). The group sizes were as follows: vehicle-treated/saline IVSA $(n=10)$, vehicle-treated/nicotine IVSA $(n=17)$, STZ-treated/nicotine IVSA $(n=16)$, STZ-treated + insulin/nicotine IVSA $(n=13)$, and vehicle-treated + insulin/nicotine IVSA $(n=8)$. The asterisks $(*)$ denote a significant difference from vehicle-treated/saline IVSA rats, and the daggers $(\dagger)$ denote a difference from all other groups $(p \leq 0.05)$

amylin levels than vehicle-treated rats that pressed for nicotine $\left({ }^{\#} p \leq 0.0001\right)$, suggesting that our insulin regimen increased amylin levels. There were no differences in amylin levels between vehicle- and STZ-treated + insulin rats. The analysis of GLP-1 (panel $D$ ) revealed a main effect of treatment $\left[F_{(4,43)}=3.83, p \leq\right.$ $0.01]$. STZ-treated rats displayed higher levels of GLP-1 than vehicle-treated rats that pressed for nicotine $\left({ }^{\#} p \leq 0.01\right)$, an effect that illustrates STZ-induced increases in GLP-1 levels. Also, vehicletreated rats that received insulin displayed an increase in GLP-1 levels as compared to vehicle-treated rats that pressed for nicotine ( $\left.{ }^{\#} p \leq 0.0001\right)$, suggesting that insulin enhanced GLP-1 levels alone.
There were no differences in GLP-1 levels between vehicle- and STZ-treated + insulin rats.

Figure 4 illustrates mean protein levels $( \pm$ SEM) of pIRS- 2 and IGF-1R $\beta$ in the NAc and VTA. The analysis of pIRS-2 revealed a significant interaction between treatment and brain region $\left[F_{(2,28)}\right.$ $=16.46, p \leq 0.0001]$. In the NAc (panel A), post-hoc analysis revealed that STZ-treated rats displayed lower levels of pIRS-2 as compared to all other groups $\left({ }^{\dagger} p \leq 0.0001\right)$. There was no difference in pIRS-2 levels between vehicle- and STZ-treated + insulin rats. In the VTA (panel B), post-hoc analysis revealed that both groups of STZ- and STZ-treated + insulin rats displayed 
Saline IVSA

$\square$ Vehicle-treated
Nicotine IVSA

$\bigoplus$ Vehicle-treated

STZ-treated

STZ-treated+insulin

ख Vehicle-treated+insulin
(A)

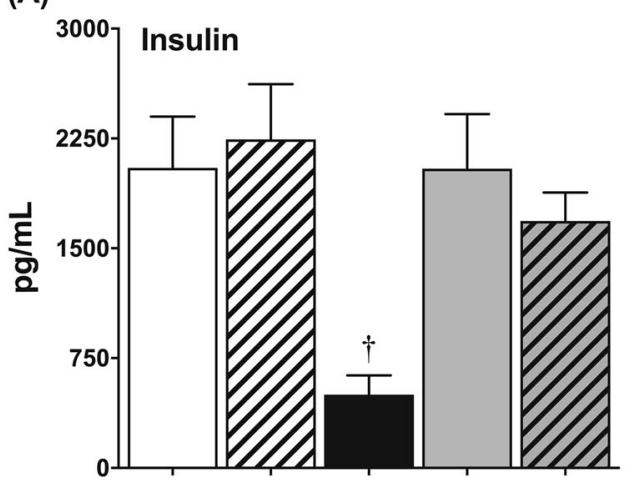

(C)

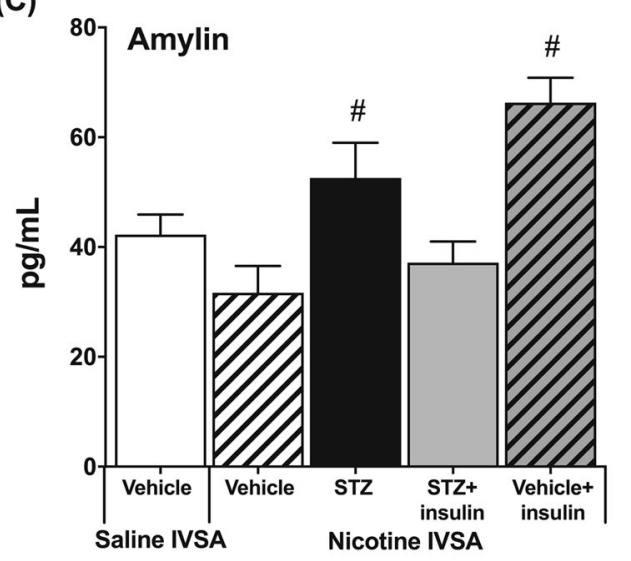

(B)

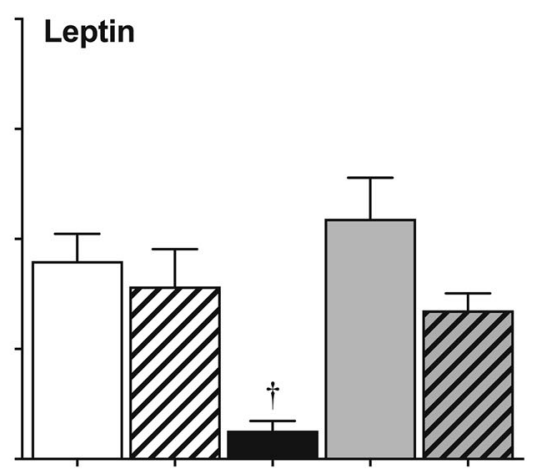

(D)

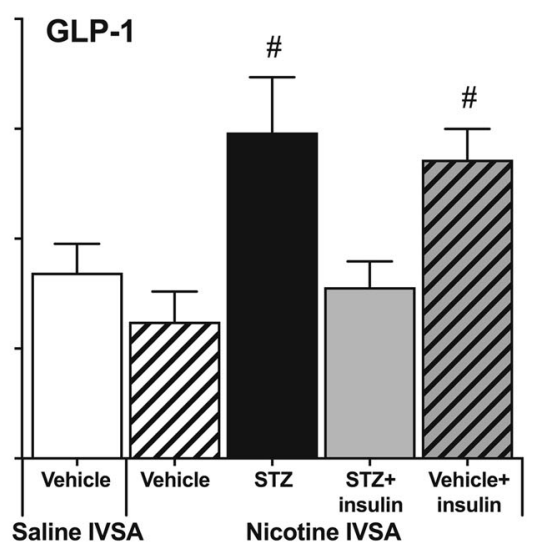

Treatment conditions

Fig. 3 Mean $( \pm$ SEM) plasma levels of insulin $(\mathbf{A})$, leptin $(\mathbf{B})$, amylin $(\mathbf{C})$, and GLP-1 (D) collected after the last IVSA session. The daggers ( + ) denote a significant difference from all other groups $(p \leq 0.05)$, and the number signs (\#) denote a difference from vehicle-treated rats that pressed for nicotine

higher levels of pIRS-2 as compared to vehicle-treated controls $\left({ }^{*} p \leq 0.0001\right)$. Also, STZ-treated + insulin rats displayed higher levels of pIRS-2 as compared to STZ-treated rats ( $\left.{ }^{*} p \leq 0.0001\right)$, suggesting that insulin produced a further enhancement of pIRS-2 levels in the VTA.

The analysis of IGF-1R $\beta$ revealed a significant interaction between treatment and brain region $\left[F_{(2,29)}=5.31, p \leq 0.01\right]$. In the NAC (panel C), post-hoc analysis revealed that STZ-treated rats displayed lower levels of IGF-1R $\beta$ as compared to all other groups $\left({ }^{\dagger} p \leq 0.0001\right)$. There was no difference in IGF-1R $\beta$ levels between vehicle- and STZ-treated + insulin rats. In the VTA (panel D), posthoc analysis revealed that STZ-treated + insulin rats displayed higher levels of IGF-1R $\beta$ as compared to vehicle-treated controls $\left({ }^{*} p \leq 0.0001\right)$.

\section{DISCUSSION}

\section{Summary}

The present study revealed that STZ-treated rats displayed an increase in plasma glucose levels, body weight, food intake, and water responses. The pattern of changes in these measures was prevented in STZ-treated rats that also received insulin, consistent with another report using the same insulin supplementation procedure [27]. The finding that insulin prevented STZ-induced increases in glucose levels, food intake, and water responses to vehicle-treated control levels provides verification of the induction and reversal of hypoinsulinemia, a hallmark physiological effect of diabetes. The major finding of Study 1 was that STZ-treated rats displayed greater reinforcing effects of nicotine relative to vehicletreated rats, and this effect was returned to control levels in STZtreated rats that also received insulin. STZ-treated rats also displayed a decrease in insulin and leptin and an increase in amylin and GLP-1 plasma levels, and the pattern of these changes were returned to control levels in STZ-treated rats that received insulin. STZ-treated rats also displayed a decrease in pIRS-2 and IGF-1R $\beta$ levels in the NAc, and this pattern of changes was also reduced to control levels in STZ-treated rats that received insulin supplementation. Also, STZ-treated rats that received insulin supplementation displayed an increase in pIRS-2 and IGF-1R $\beta$ levels in the VTA, suggesting that an enhancement of insulin systems in the VTA may have promoted the behavioral effects observed in this group. 


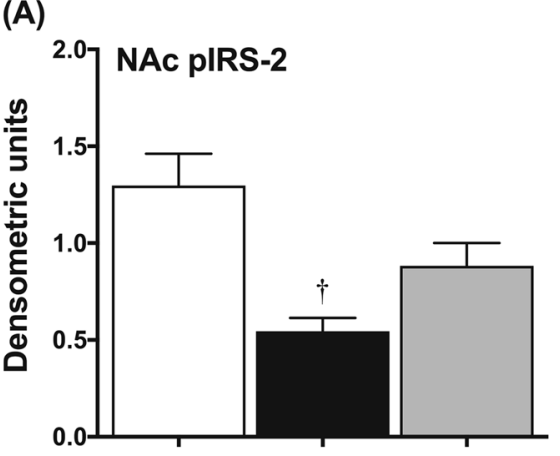

(C)

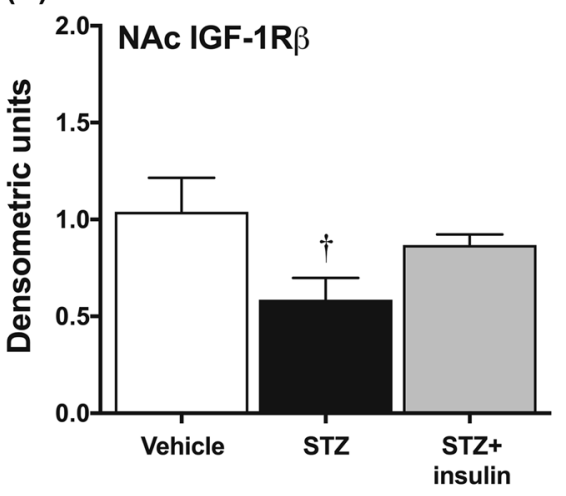

(B)

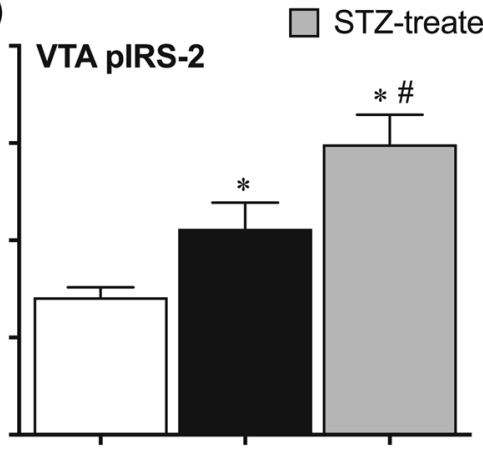

(D)

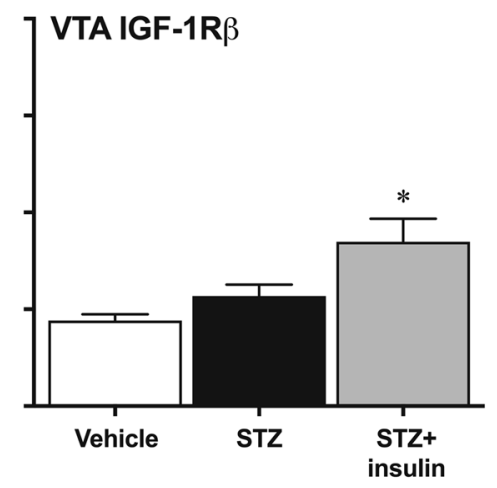

Treatment conditions

Fig. 4 Mean ( \pm SEM) protein levels of pIRS-2 (A, B) and IGF-1R $($ C, D) in the NAc (left panels) and VTA (right panels). The group sizes were as follows: vehicle-treated $(n=6)$, STZ-treated $(n=6)$, and STZ-treated + insulin $(n=5)$. The asterisks $(*)$ denote a significant difference from vehicle-treated rats, and the daggers $(\dagger)$ denote a difference from all other groups $(p \leq 0.05)$

Reinforcing effects of nicotine

The present study revealed that STZ administration enhanced nicotine IVSA across a range of doses as compared to vehicletreated rats, consistent with previous research from our laboratory using extended access to nicotine IVSA procedures [8]. The notion that STZ enhances the rewarding effects of nicotine is consistent with previous work showing that STZ enhances CPP produced by nicotine [7], an effect that is normalized to control levels following insulin supplementation [21]. Previous research has also revealed that insulin-resistant rats that were fed a high fat diet (HFD) displayed greater CPP produced by nicotine as compared to noninsulin-resistant rats that received the HFD regimen [28]. Together, these findings suggest that a lack of insulin signaling enhances the reinforcing effects of nicotine.

Insulin biomarkers

STZ administration altered plasma metabolic biomarkers, and the pattern of changes in these biomarkers were returned to control levels following insulin supplementation. Specifically, STZ-treated rats displayed a decrease in insulin and leptin, consistent with a previous report showing that STZ administration blunted insulin and leptin release [29]. Given the role of insulin and leptin in regulating satiety and consummatory behaviors, the reduction in insulin and leptin likely contributed to the increase in food intake and water responses observed in STZ-treated rats [30, 31]. STZtreated rats also displayed an increase in amylin and GLP-1 levels as compared to vehicle-treated rats. The direction of these changes is consistent with the anorectic effects of amylin, as administration of this metabolic biomarker has been shown to induce weight loss in rodents [13]. Moreover, long-term administration of amylin or an amylin agonist induces weight loss $[13,32]$. With regard to GLP-1, this hormone stimulates the synthesis and secretion of insulin [33], and elevated levels of GLP1 are associated with weight loss [34, 35]. Plasma levels of GLP-1 also increase following food consumption, and the release of GLP1 prevents pancreatic $\beta$-cell death [34]. Thus, it is possible that STZ-treated rats displayed higher levels of GLP-1 in response to lower levels of plasma insulin.

Insulin in the mesolimbic system

The changes in insulin-signaling proteins were focused in the NAc, a terminal region of the mesolimbic reward pathway. Specifically, STZ-treated rats displayed a down-regulation of NAC pIRS- 2 and IGF-1R $\beta$ levels that were returned to control levels in STZ-treated rats that received insulin. Consistent with previous findings, STZtreated rats displayed a decrease in pIRS-2 levels in the NAc relative to controls [20]. Previous work has also shown that STZ administration decreases IRS-2 signaling in the hippocampus [36, 37] and hypothalamus [38], and the latter effect was returned to control levels following viral-mediated over-expression of IRS-2 levels. Interestingly, the levels of pIRS-2 and IGF-1R $\beta$ were increased in the VTA of STZ-treated rats that received insulin relative to vehicle-treated controls, suggesting that the insulin supplementation regimen stimulated pIRS-2 and IGF-1R $\beta$ signaling in the VTA. Together, these findings suggest that the strong reinforcing effects of nicotine observed in STZ-treated rats are modulated via insulin systems in the NAc.

A critical common denominator in metabolic signaling downstream of the actions of insulin, leptin, and GLP-1 are their effects on blood glucose levels and the resulting decrease in glucose 
levels upon insulin treatment. Glucose has been shown to have direct effects on increasing and decreasing mesolimbic dopamine neuronal activity in a concentration-dependent manner [39]. Glucose is also capable of producing rewarding effects independent of its sweet taste, as evident by CPP evoked following intragastric glucose administration [40]. In fact, recent work in our laboratory has shown that the strong rewarding effects of nicotine observed in STZ-treated rats can be attenuated by direct normalization of blood glucose levels with dapagliflozin, a sodium-glucose type 2 transport inhibitor [21]. Importantly, a prior study revealed that administration of a GLP-1 receptor agonist (Exendin-4) reduces nicotine-induced CPP, locomotor activity, and increases in NAc dopamine release compared to controls [41]. Also, administration of a GLP-1 agonist into the interpeduncular nucleus reduced IVSA as compared to controls [42]. Also, viral-mediated gene activation of GLP-1 neurons in the nucleus tractus solitarius has been shown to reduce nicotine IVSA as compared to controls [42]. The latter study also demonstrated that viral-mediated knockdown of GLP-1 receptors in the medial habenula promoted nicotine IVSA compared to controls. The latter findings along with the present results suggest that the rewarding effect of nicotine are enhanced in diabetic rodents via a complex interplay of different metabolic factors.

It has been hypothesized that the high propensity of tobacco use among patients with diabetes is modulated via reduced dopamine transmission in the mesolimbic pathway (see [20]). Indeed, dampened dopaminergic systems may promote other compulsive behaviors, such as overeating [43-45]. It is possible that the lack of insulin produced by diabetes suppresses dopamine systems in a manner that promotes tobacco use in an attempt to increase dopamine transmission. In line with this suggestion, STZtreated rats displayed higher brain reward thresholds than healthy controls using intracranial self-stimulation procedures, an indication of a reward deficiency syndrome [22]. The latter effect was normalized to control levels following insulin supplementation. The manner in which a disruption in insulin signaling produced by diabetes alters dopamine systems is unclear. However, recent evidence suggests that insulin facilitates dopamine transmission via cholinergic interneurons in the NAc [19]. The latter study demonstrated that insulin administration enhanced dopamine release in NAc indirectly via activation of insulin receptors expressed on cholinergic interneurons. Thus, it is possible that diabetes reduces insulin receptor activation in striatal cholinergic interneurons, thereby attenuating dopamine release in the NAc. Indeed, STZ-treated rats displayed a reduction in nicotine-induced dopamine release in the NAC [8]. STZ-treated rats also displayed an up-regulation of dopamine transporters (DAT) in the NAc, an effect that is likely related to greater clearance of extracellular dopamine in STZ-treated rats. STZ-treated rats also displayed a larger downregulation of dopamine D1-receptors in the NAC as compared to controls, an effect that is likely due to chronic low levels of dopamine observed in STZ-treated rats [8].

\section{Other drugs of abuse}

Prior studies have produced mixed results with regard to the rewarding effects of drugs of abuse other than nicotine in STZtreated rats. For example, STZ-treated rats displayed similar levels of cocaine IVSA as compared to vehicle-treated rats [46]. However, STZ-treated rats displayed a reduction in the magnitude of cocaine-induced CPP relative to vehicle-treated rats [47]. STZtreated rats displayed less amphetamine IVSA relative to vehicletreated rats $[46,48]$. The latter study also found no differences in the magnitude of amphetamine-induced CPP in vehicle- versus STZ-treated rats [48]. STZ-treated rats displayed a larger magnitude of CPP produced by methamphetamine $[49,50]$ and morphine [51, 52]. Previous work has also shown that STZtreated rats displayed greater sensitivity to the behavioral effects (locomotor activity, catalepsy, and yawning) of dopamine D2/D3 receptor agonists $[27,53]$. This increase in dopamine receptor sensitivity produced by STZ was reduced to control levels following insulin supplementation [27]. The latter finding is consistent with the present finding that the pattern of changes in behavior and biological markers induced by STZ are returned to control levels following insulin supplementation.

\section{Other considerations}

The possibility exists that STZ produced an array of biological consequences that may have influenced our IVSA results. With regard to body weight, the concentration of nicotine was adjusted daily for each rat in order to account for the reduction in body weight across our experimental timeline with diabetic rodents. With regard to fluid loss produced by excessive urination, a previous study revealed that STZ-treated rats displayed lower levels of saline versus nicotine IVSA [8]. Thus, it does not appear that STZ-treated rats self-administered more nicotine in an attempt to increase fluid levels. Another potential consideration is that STZ-treated rats display tactile allodynia and cataract formation [54,55], and these effects of STZ could have disrupted IVSA behavior. However, the emergence of these side effects of STZ occurs at a later time point that exceeds our 12-day period of IVSA $[56,57]$. Furthermore, the present study found that STZtreated rats displayed robust increases in operant responding for nicotine, food, and water that did not appear to be altered by the emergence of any negative effects of STZ. Another important consideration is that vehicle-treated rats that received insulin displayed a hypoglycemic state below vehicle-treated controls. This effect of insulin might explain the increases in food intake, weight change, GLP-1, and amylin levels that were observed in insulin-treated rats. Indeed, GLP-1 levels have been shown to increase in procedures that enhanced food consumption in rodents [34]. Also, administration of amylin has been shown to produce a hypoglycemic state in healthy mice, suggesting that hypoglycemia may produce elevated amylin levels in rodents [58]. Lastly, the possibility exists that STZ-treated rats may display an altered metabolic rate of nicotine that could have influenced our nicotine IVSA results. However, a previous study in our laboratory revealed that STZ-treated rats displayed similar plasma levels of the nicotine metabolic cotinine as compared to control rats [8].

\section{Clinical implications}

There are several clinical implications to consider from this report. First, these results suggest that a lack of insulin signaling promotes the strong rewarding effects of nicotine in patients with diabetes. There are converging lines of evidence suggesting that suppressed insulin signaling impairs dopamine transmission in both humans and rodent models [8, 59-64]. Thus, pharmacological interventions that normalize insulin signaling and dopamine deficits may reduce tobacco use in patients with diabetes. As a result, maintaining proper glycemic control may be critical for diabetic patients seeking to reduce drug use and/or smoking behavior. Another rodent study revealed that IRS-2 knockout mice displayed impaired insulin signaling and glucose tolerance [65]. Thus, pharmacotherapies that facilitate IRS-2 signaling should be considered as potential tools to reduce the strong rewarding effects of nicotine that may promote tobacco use in patients with diabetes. Future studies are needed to assess the role of glucose in modulating the rewarding effects of nicotine, especially given the finding that dapagliflozin (Farxiga ${ }^{\circ}$ ), a sodium-glucose transport inhibitor normalized CPP produced by nicotine in STZ-treated rats [21]. Also, a recent study revealed that administration of glucophage (Metformin), a medication used to treat Type 2 diabetes reduced anxiety-like behaviors produce by nicotine withdrawal in mice [66]. It is recognized that different biological consequences may accompany the absence of insulin versus the insensitivity to insulin. These distinct etiological origins of Type 1 versus Type 2 diabetes may require different smoking cessation 
remedies in patients who suffer from different types of diabetes. Future studies are needed to assess the neurobiological substrates by which diabetes enhances tobacco use vulnerability in patients with diabetes.

\section{FUNDING AND DISCLOSURE}

The authors declare no conflict of interest. The present study was supported by the American Diabetes Association (7-12-BS-135), the National Institute on Drug Abuse (R15-DA040130; R01-DA021274; HHSN271201600057C; R25-DA033613), and the Research Initiative for Scientific Enhancement (RISE) Program (R25-GM069621).

\section{ADDITIONAL INFORMATION}

Publisher's note: Springer Nature remains neutral with regard to jurisdictional claims in published maps and institutional affiliations.

\section{REFERENCES}

1. Bishop FK, Maahs DM, Snell-Bergeon JK, Ogden LG, Kinney GL, Rewers M. Lifestyle risk factors for atherosclerosis in adults with type 1 diabetes. Diab Vasc Dis Res. 2009;64:269-75.

2. Gill GV, Morgan C, MacFarlane IA. Awareness and use of smoking cessation treatments among diabetic patients. Diabet Med. 2005;22:658-60.

3. Haire-Joshu D, Heady S, Thomas L, Schechtman K, Fisher EB. Depressive symptomatology and smoking among persons with diabetes. Res Nurs Health. $1994 ; 17: 273-82$

4. Spangler JG, Summerso JH, Bell RA, Konen JC. Smoking status and psychosocial variables in type 1 diabetes mellitus. Addict Behav. 2006;26:21-9.

5. Scemama O, Hamo-Tchatchouang E, Le Faou AL, Altman JJ. Difficulties of smoking cessation in diabetic inpatients benefiting from a systematic consultation to help them to give up smoking. Diabetes Metab. 2006;32:435-41.

6. Tonstad S. Cigarette smoking, smoking cessation, and diabetes. Diabetes Res Clin Pract. 2009:85:4-13.

7. Pipkin JA, Cruz B, Flores RJ, Hinojosa CA, Carcoba LM, Ibarra M, et al. Both nicotine reward and withdrawal are enhanced in a rodent model of diabetes. Psychopharmacology. 2017;234:1615-22.

8. O'Dell LE, Natividad LA, Pipkin JA, Roman F, Torres I, Jurado J, et al. Enhanced nicotine self-administration and suppressed dopaminergic systems in a rat model of diabetes. Addict Biol. 2014;19:1006-19.

9. Lenzen S. The mechanisms of alloxan- and streptozotocin-induced diabetes. Diabetologia. 2008;51:216-26.

10. Ferrario $\mathrm{CR}$, Labouèbe $\mathrm{G}$, Liu $\mathrm{S}$, Nieh $\mathrm{EH}$, Routh $\mathrm{VH}$, $\mathrm{Xu} \mathrm{S}$, et al. Homeostasis meets motivation in the battle to control food intake. J Neurosci. 2016;36:11469-81.

11. Narayanan NS, Guarnieri DJ, DiLeone RJ. Metabolic hormones, dopamine circuits, and feeding. Front Neuroendocrinol. 2010;31:104.

12. Figlewicz DP, Evans SB, Murphy J, Hoen M, Baskin DG. Expression of receptors for insulin and leptin in the ventral tegmental area/substantia nigra (VTA/SN) of the rat. Brain Res. 2003;964:107-15.

13. Mietlicki-Baase EG, Olivos DR, Jeffrey BA, Hayes MR. Cooperative interaction between leptin and amylin signaling in the ventral tegmental area for the control of food intake. Am J Physiol Endocrinol Metab. 2015;308:1116-22.

14. Koob GF. Neurobiology of addiction. Toward the development of new therapies. Ann N Y Acad Sci. 2000;909:170-85.

15. Koob GF, Kreek MJ. Stress, dysregulation of drug reward pathways, and the transition to drug dependence. Am J Psychiatry. 2007;164:1149-59.

16. Mansvelder HD, De Rover M, McGehee DS, Brussaard AB. Cholinergic modulation of dopaminergic reward areas: upstream and downstream target of nicotine addiction. Eur J Pharmacol. 2003;480:117-23.

17. Havrankova J, Roth J, Brownstein M. Insulin receptors are widely distributed in the central nervous system of the rat. Nature. 1978;272:388-94.

18. Unger JW, Livingston JN, Moss AM. Insulin receptors in the central nervous system: localization, signalling mechanisms and functional aspects. Prog Neurobiol. 1991;36:343-62.

19. Stouffer MA, Woods CA, Patel JC, Lee CR, Witkovsky P, Bao L, et al. Insulin enhances striatal dopamine release by activating cholinergic interneurons and thereby signals reward. Nat Commun. 2015;6:8543.

20. O'Dell LE, Nazarian A. Enhanced vulnerability to tobacco use in persons with diabetes: a behavioral and neurobiological framework. Prog NeuroPsychopharmacol Biol Psychiatry. 2016;65:288-96.

21. Íbias J, O'Dell LE, Nazarian A. Insulin dependent and independent normalization of blood glucose levels reduces the enhanced rewarding effects of nicotine in a rodent model of diabetes. Behav Brain Res. 2018;17:31855-67.
22. Ho N, Balu DT, Hilario MRF, Blendy JA, Lucki I. Depressive phenotypes evoked by experimental diabetes are reversed by insulin. Physiol Behav. 2012;105: 702-8.

23. Flores RJ, Pipkin JA, Uribe KP, Perez A, O'Dell LE. Estradiol promotes the rewarding effects of nicotine in female rats. Behav Brain Res. 2006;307: 258-63.

24. Natividad LA, Torres OV, Friedman TC, O'Dell LE. Adolescence is a period of development characterized by short- and long-term vulnerability to the rewarding effects of nicotine and reduces sensitivity to the anorectic effect of this drug. Behav Brain Res. 2013;257:275-85.

25. O'Dell LE, Koob GF. 'Nicotine deprivation effect' in rats with intermittent 23-hour access to intravenous self-administration. Pharmacol Biochem Behav. 2007:86:346-53.

26. Ramos J, Hernandez-Casner C, Cruz B, Serafine KM. Sex differences in high fat diet-induced impairments to striatal Akt signaling and enhanced sensitivity to the behavioral effects of dopamine D2/D3 receptor agonist quinpirole. Physiol Behav. 2017;9384:30406-7.

27. Sevak RJ, Koek W, Galli A, France CP. Insulin replacement restores the behavioral effects of quinpirole and raclopride in streptozotocin-treated rats. J Pharmacol Exp Ther. 2007;320:1216-23.

28. Richardson JR, Pipkin JA, O'Dell LE, Nazarian A. Insulin resistant rats display enhanced rewarding effects of nicotine. Drug Alcohol Depend. 2014;140:205-7.

29. Havel PJ, Uriu-Hare JY, Liu T, Stanhope KL, Stern JS, Keen CL, et al. Marked and rapid decreases of circulating leptin in streptozotocin diabetic rats: reversal by insulin. Am J Physiol. 1998;274:1482-91.

30. Figlewicz DP, Sipols AJ. Energy regulatory signals and food reward. Pharmacol Biochem Behav. 2010;97:15-24.

31. Stice E, Figlewicz DP, Gosnell BA, Levine AS, Pratt WE. The contribution of brain reward circuits to the obesity epidemic. Neurosci Biobehav Rev. 2012;37:1-12.

32. Lutz TA. Control of energy homeostasis by amylin. Cell Mol Life Sci. 2012;69:1947-65.

33. Lee YS, Jun HS. Anti-diabetic actions of glucagon-like peptide-1 on pancreatic beta-cells. Metabolism. 2014;63:9-19.

34. Keleidari B, Mofrad RM, Shahmiri SS, Sanei MH, Kolahdouzan M, Sheikhbahaei E. The impacts of gastroileostomy rat model on glucagon-like peptide-1: a promising model to control type 2 diabetes mellitus. Obes Surg. 2018;28:1-7.

35. Koliaki C, Doupis J. Incretin-based therapy: a powerful and promising weapon in the treatment of type 2 diabetes mellitus. Diabetes Ther. 2011;2:101-21.

36. Li Z, Zhang W, Grunberger G, Sima AAF. Hippocampal neuronal apoptosis in type 1 diabetes. Brain Res. 2002;946:212-31.

37. Gomes RJ, de Oliveira CA, Ribeiro C, Mota CS, Moura LP, Tognoli LM, et al. Effects of exercise training on hippocampus concentrations of insulin and IGF-1 in diabetic rats. Hippocampus. 2009;10:981-7.

38. Gelling RW, Morton GJ, Morrison CD, Niswender KD, Myers MG Jr, Rhodes CJ, et al. Insulin action in the brain contributes to glucose lowering during insulin treatment of diabetes. Cell Metab. 2006;3:67-73.

39. Levin BE. Glucose-regulated dopamine release from substantia nigra neurons. Brain Res. 2000;874:158-64.

40. Ren X, Ferreira JG, Zhou L, Shammah-Lagnado SJ, Yeckel CW, de Araujo IE. Nutrient selection in the absence of taste receptor signaling. J Neurosci. 2010;30:8012-23.

41. Egecioglu E, Engel JA, Jerlhag E. The glucagon-like peptide 1 analogue Exendin-4 attenuates the nicotine-induced locomotor stimulation, accumbal dopamine release, conditioned place preference as well as the expression of locomotor sensitization in mice. PLoS One. 2013;8:e77284.

42. Tuesta LM, Chen Z, Duncan A, Fowler CD, Ishikawa M, Lee BR, et al. GLP-1 acts on habenular avoidance to control nicotine intake. Nat Neurosci. 2017;20:708-16.

43. Blum K, Braverman ER, Holder JM, Lubar JF, Monastra VJ, Miller D, et al. Reward deficiency syndrome: a biogenetic model for the diagnosis and treatment of impulsive, addictive, and compulsive behaviors. J Psychoactive Drugs. 2000;32:1-112.

44. Blum K, Chen AL, Chen TJ, Braverman ER, Reinking J, Blum SH, et al. Activation instead of blocking mesolimbic dopaminergic reward circuitry is a preferred modality in the long-term treatment of reward deficiency syndrome (RDS): a commentary. Theor Biol Med Model. 2008;5:24.

45. Fineberg NA, Potenza MN, Chamberlain SR, Berlin HA, Menzies L, Bechara A, et al. Probing compulsive and impulsive behaviors, from animal models to endophenotypes: a narrative review. Neuropsychopharmacology. 2010;35:591-604.

46. Galici R, Galli A, Jones DJ, Sanchez TA, Saunders C, Frazer A, et al. Selective decreases in amphetamine self-administration and regulation of dopamine transporter function in diabetic rats. Neuroendocrinology. 2003;77:132-40.

47. Kamei J, Ohsawa M. Effects of streptozotocin-induced diabetes on place conditioning action of cocaine in mice. J Pharmacol. 1997;75:299-301.

48. Sevak RJ, Owens WA, Koek W, Galli A, Daws LC, France CP. Behavioral effects of amphetamine in streptozotocin-treated rats. Eur J Pharmacol. 2008;581:105-12. 
49. Bayat $A H$, Haghparast $A$. Effect of insulin deficiency on the rewarding properties of methamphetamine in streptozotocin-induced diabetic rats. Pharmacol Biochem Behav. 2015;128:8-13.

50. Kamei J, Ohsawa M. Effects of diabetes on methamphetamine-induced place preference in mice. Eur J Pharmacol. 1996;318:251-6.

51. Kamei J, Ohsawa M, Suzuki T, Nagase H. Modification of morphine-induced place preference by diabetes. Eur J Pharmacol. 1997;337:137-45.

52. Samandari R, Chizari A, Hassanpour R, Mousavi Z, Haghparast A. Streptozotocininduced diabetes affects the development and maintenance of morphine reward in rats. Neurosci Lett. 2013;543:90-4.

53. Sevak RJ, Koek W, France CP. Streptozotocin-induced diabetes differentially modifies haloperidol- and $\gamma$-hydroxybutyric acid (GHB)-induced catalepsy. Eur J Pharmacol. 2005;517:64-7.

54. Morrow TJ. Animal models of painful diabetic neuropathy: the STZ rat model. Curr Protoc Neurosci. 2004. https://doi.org/10.1002/0471142301.ns0918s29.

55. Wei M, Ong L, Smith MT, Ross FB, Schmid K, Hoey AJ, et al. The streptozotocindiabetic rat as a model of the chronic complications of human diabetes. Heart Lung Circ. 2003;12:44-50.

56. Egger M, Smith GD, Stettler C, Diem P. Risk of adverse effects of intensified treatment in insulin-dependent diabetes mellitus: a meta-analysis. Diabet Med. 1997;14:919-28.

57. Febo F, Molinari C, Piatti PM. Hypoglycemia and insulin treatment. J Endocrinol Invest. 2011;34:698-701.
58. Guerreiro LH, Da Silva D, Sola-Penna M, Mizurini DM, Lima LM. Amylin induces hypoglycemia in mice. Acad Bras Cienc. 2013;85:349-54.

59. Caravaggio F, Borlido C, Hahn M, Feng Z, Fervaha G, Gerretsen P, et al. Reduced insulin sensitivity is related to less endogenous dopamine at $D_{2 / 3}$ receptors in the ventral striatum of healthy nonobese humans. Int J Neuropsychopharmacol. 2015;18:pyv014.

60. Trulson ME, Himmel CD. Decreased brain dopamine synthesis rate and increased $[3 \mathrm{H}]$ spiroperidol binding in streptozotocin-diabetic rats. J Neurochem. 1983;40: $1456-9$.

61. Lackovic Z, Salkovic M, Kuci Z, Relja M. Effect of long-lasting diabetes mellitus on rat and human brain monoamines. J Neurochem. 1990;54:143-7.

62. Kono T, Takada M. Dopamine depletion in nigrostriatal neurons in the genetically diabetic rat. Brain Res. 1994;634:155-8.

63. Crandall EA, Fernstrom JD. Effect of experimental diabetes on the levels of aromatic and branched-chain amino acids in rat blood and brain. Diabetes. 1983;32:222-30

64. Bitar M, Koulu M, Rapoport SI, Linnoila M. Diabetes-induced alteration in brain monoamine metabolism in rats. J Pharmacol Exp Ther. 1986;236:432-7.

65. Withers DJ, Gutierrez JS, Towery H, Burks DJ, Ren JM, Previs S, et al. Disruption of IRS-2 causes type 2 diabetes in mice. Nature. 1998;391:900-4.

66. Brynildsen JK, Lee BG, Perron IJ, Jin S, Kim SF, Blendy JA. Activation of AMPK by metformin improves withdrawal signs precipitated by nicotine withdrawal. Proc Natl Acad Sci USA. 2018;115:4282-7. 